Article

\title{
Influences of Doping and Crystal Orientation on Surface Roughening upon Alcohol Grafting onto Silicon Hydride
}

\author{
Joline Tung ${ }^{1}$ and Yit Lung Khung ${ }^{2, *}$ \\ 1 College of Arts and Sciences, University of North Carolina at Chapel Hill (UNC), Chapel Hill, NC 27514, USA; \\ jolinet@live.unc.edu \\ 2 Institute of New Drug Development, China Medical University, No. 91 Hsueh-Shih Road, Taichung 40402, Taiwan \\ * Correspondence: yitlung.khung@mail.cmu.edu.tw; Tel.: +886-04-2205-3366
}

Received: 12 July 2017; Accepted: 18 August 2017; Published: 21 August 2017

\begin{abstract}
An alcohol bearing alkyne was thermally grafted to both $p$-type and $n$-type silicon (111) and (100) substrate of comparable doping levels and surface flatness. The surface topography as well as the surface chemistry was examined via atomic force microscopy (AFM), X-ray photoelectron spectroscopy (XPS) and water contact angle measurements. P-type silicon (111) was observed to experience roughening on the surface upon functionalization while $n$-type silicon (111) surfaces remained relatively unchanged. When the alcohol was grafted onto silicon (100) surface, the roughening effect was found to be even more profound for the $p$-type while the effects were marginal for the $n$-type surfaces. Both roughening effects were attributed to the differential weakening of the $\mathrm{Si}-\mathrm{Si}$ backbond induced by majority carriers in $p$ - and $n$-type silicon while (111) was observed to be able to resist the roughening effect better and this was explained by the notion of its denser adatom surface packing as well as the presence of surface defects.
\end{abstract}

Keywords: silicon (111) and (100); surface etching; dopant

\section{Introduction}

Hydrosilylation on silicon surface remains a relatively useful technique for the passivation of silicon surface with organic monolayers but the process is extremely sensitive towards water contamination due to the susceptibility of water molecules reacting with surface radicals [1-3]. On the other hand, thermal-based hydrosilylation is another alternative that works at higher temperature $\left(150-200{ }^{\circ} \mathrm{C}\right)$ that may ensure that water within from solvent is kept minimal to reduce the chances of oxidation. Recent models of thermal reactions do suggest that the surface reaction to form a stable Si-C linkage can proceed at lower temperatures $\left(<150{ }^{\circ} \mathrm{C}\right)$ as reported by Horrock et al. [4] but at these lower temperatures, hydrogenated silicon surface can also be prone to nucleophilic reactions $[5,6]$. Of these, surface reaction between alcohol and hydrogenated Silicon $(\mathrm{Si}-\mathrm{H})$ was well established in literature and many other reports had shown the formation of stable $\mathrm{Si}-\mathrm{O}-\mathrm{C}$ linkage towards the surface [7-10].

Nonetheless, the exact mechanism for thermal hydrosilylation had remained relatively elusive for several reasons. To begin with, it is important to consider the issue of steric hindrance for Sieval et al. simply stated that a full passivation cannot be attained due to the proximity of the silicon adatoms [11,12]. It was also increasingly clear that even at temperatures above $150{ }^{\circ} \mathrm{C}$, the nominal silicon hydride homolysis may not be the initiating process on silicon surfaces as described by Coletti et al. and there might be the contention of surface silicon dimerization, especially in ultra high vacuum conditions [13]. However, such a description may not be fully accepted within the scientific community currently. With regards to UV photoionization, the process has also been under some 
scrutiny in recent years with the notion of excitons taking main stage of the underlying process [14,15]. Hence, the need to elicit the exact silicon surface reactivity under the various conditions remains relatively pressing despite the huge stride made in literature. Yet, it was noticeable that a majority of research did not take into account the nature of the doping together in conjunction with crystal lattice type. However, it has to be said that some inroads were made by Hamers et al. using visible light passivation on silicon (111) and (100) surfaces [16]. Overall, the link between these physical attributes and how they may ultimately influence surface reaction outcome has remained relatively obscure.

Previously, our group has also demonstrated the preference of hydrogenated silicon towards nucleophilic additions with alcohol ends of alkynes $[6,17,18]$. In fact, many reports have shown the susceptibility of alcohol grafting on silicon-hydride surfaces [4,7]. Upon the formation of the Si-O-C bond, studies showed that the presence of water could induce surface roughening but what is more interesting is that roughening proceeds differently depending on the doping of the silicon substrate. As reported by Hacker et al. [7], boron doped $p$-type silicon was observed to develop an overall rougher surface while in $n$-type samples roughening is generally localized along the step edges of atomically flat terraces [8]. Basically, while the description for this phenomenon has always been depicted as being due to 'water contamination', the underlying topographical differences may suggest an even richer underlying chemistry. Therefore, to further understand this chemistry, we examined the resultant surfaces upon functionalization with alcohol on both $p$ - and $n$-type silicon at comparable doping levels as well as of two different crystal orientations, (111) and (100). The aims of this work are to attempt to establish a tangible link between crystal orientation as well as doping nature and this report suggests that these effects may be manifest to subtly influence the outcome of the alcohol grafting.

\section{Materials and Methods}

\subsection{Materials}

P-type Silicon wafer (111), boron-doped (0.01-0.018 $\Omega \mathrm{cm}$ ) and n-type silicon (111), phosphorus-doped $(0.01-0.02 \Omega \mathrm{cm})$ were used in this experiment. For the silicon (100) samples, $p$-type (100) boron doped (0.001-0.005 $\Omega \mathrm{cm})$ and $n$-type (100) arsenic doped $(0.001-0.005 \Omega \mathrm{cm})$ were used and all wafers were purchased from Semiconductor Wafer, Inc. (SWI, Hsinchu, Taiwan). Unless otherwise stated, all reagents were purchased from Sigma-Aldrich (St. Louis, MO, USA) and were used as received without further purification.

\subsection{Thermal Reaction Protocol}

In a setup similar to our previous reports $[6,17,18]$, all silicon wafers were cut into pieces (approximately $20 \times 20 \mathrm{~mm}^{2}$ ) and cleaned for $30 \mathrm{~min}$ in hot Piranha solution $\left(95^{\circ} \mathrm{C}, 1 \mathrm{vol} 33 \%\right.$ aqueous hydrogen peroxide to $3 \mathrm{vol} 95-97 \%$ sulfuric acid). The surface was then transferred to an aqueous $2.5 \%$ hydrofluoric acid (HF) for a duration of $30 \mathrm{~s}$ to gently remove the native silicon oxide. We believed that this short duration to remove the native oxide would not be able to contribute significantly to the overall roughening effect of the silicon surface. Subsequently, the samples were transferred to a 4-ethynylbenzyl alcohol solution (0.3 M in Mesitylene) inside a custom-made Schlenk flask that underwent a minimum of 20 freeze-pump-thaw cycles. The sample was kept under a stream of nitrogen and immersed in an oil bath set to $130^{\circ} \mathrm{C}$ for $18 \mathrm{~h}$. The flask was then opened to retrieve the surfaces and was rinsed with sonication in copious amounts of chloroform, ethyl acetate, and then ethanol before being analyzed.

\subsection{Contact Angle Measurements}

A custom made goniometer was used to capture water contact-angle values on the samples. It was comprised of a CCD camera (SMN-B050-U (B/W)) that acquired the images at a resolution of $2560 \times 1920$. For each sessile droplet measurement, three separate $2 \mu \mathrm{L}$ droplets were dispensed onto the selected sample and the droplet images were saved. All droplet images were then processed by 
Dropsnake 2.1 (http:/ /bigwww.epfl.ch/demo/dropanalysis/) that calculated both the left and right contact angles from the droplet shape with an accuracy of $\pm 0.1^{\circ}$.

\subsection{Atomic Force Microscopy}

Atomic force microscopy (AFM) images were acquired on a Digital Instrument NS4/D3100CL/ MultiMode Scanning Probe Microscope running on in-build AFM tapping mode with cantilever tuned at Freq. $150 \mathrm{kHz}$, Force $5 \mathrm{~N} / \mathrm{m}$ in triplicates. The scan area on the surfaces was $1 \mu \mathrm{m} \times 1 \mu \mathrm{m}$ and the scan speed was set at $0.6 \mathrm{~Hz}$ with the integral and proportional gain set at automatic mode. Post image processing was performed with Gwyddion MacOS version 2.38 (http:/ / gwyddion.net).

\subsection{X-ray Photoelectron Spectroscopy (XPS)}

X-ray photoelectron spectroscopy analysis was performed on a PHI 5000 VersaProbe (ULVAC-PHI, Physical Electronics, Chanhassen, MN, USA) equipped with an Al K $\alpha$ X-ray source $(1486.6 \mathrm{eV})$ and taken at an angle of $45^{\circ}$ relative to the surface. Spectra were also obtained for the $\mathrm{C} 1 \mathrm{~s}, \mathrm{O} 1 \mathrm{~s}$ and Si2p in high resolution for all samples. The spectra were subsequently analyzed and deconvoluted using XPSpeak while the atomic concentration was determined by CasaXPS (version 2.3.18, http://www.casaxps.com).

\section{Results}

From a classical hydrosilylation point of view, radicals on the surface do play an important role, being responsible for the formation of covalent linkage with unsaturated carbon to the surface. On the other hand, we decided to utilize a radical-free system forcing the surface reaction to proceed via nucleophilic insertion of the alcohol to the $\mathrm{Si}-\mathrm{H}$ bond and the subsequent abstraction of the hydrogen as described by Horrock et al. [4]. This was deliberately done so to minimize the interference from surface radicals that could influence any physical change on the surface during surface coupling. In order to examine the differences that could arise from the different doping, we decided to perform the same alcohol reaction on highly doped $n$ - and $p$-type silicon as well as on different crystal orientations as shown in Figure 1.

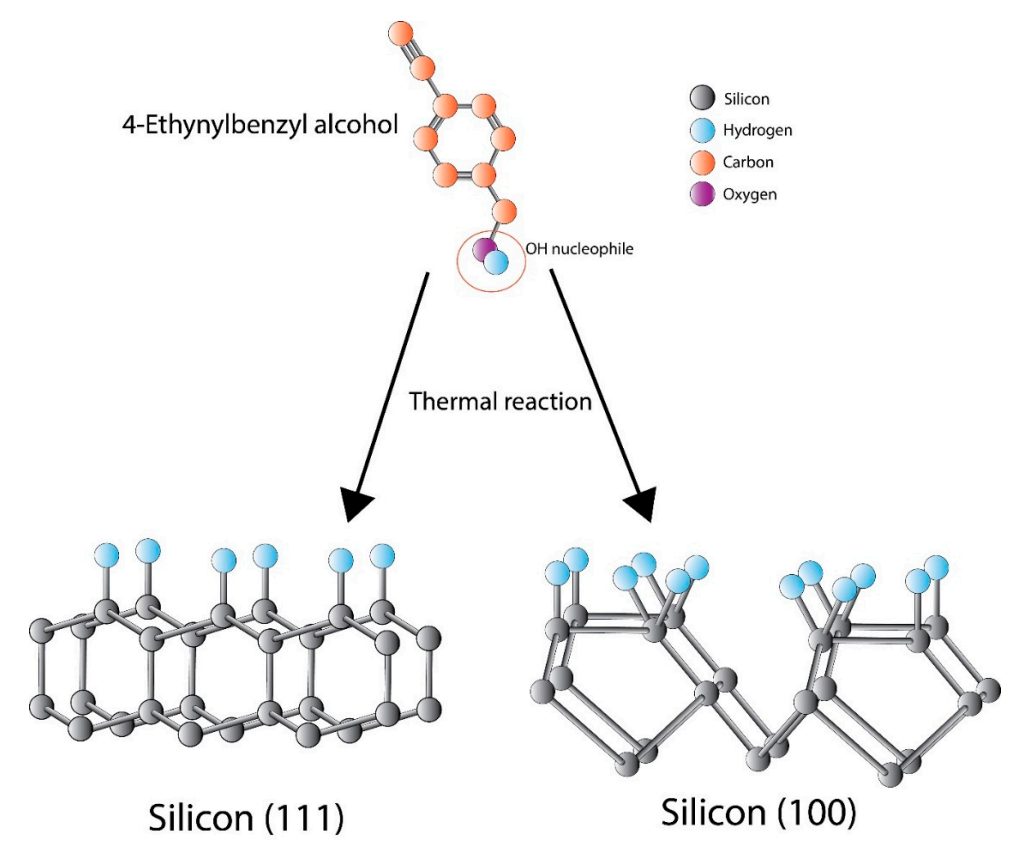

Figure 1. Illustration of the alcohol reaction to silicon hydrogenated $(\mathrm{Si}-\mathrm{H})$ surfaces of different crystal orientations. 
Firstly, it is important to take into consideration the mobility of "carriers" at elevated temperatures $\left(130{ }^{\circ} \mathrm{C} / 403 \mathrm{~K}\right)$. The process of the electron mobility (especially with regards to $n$-type silicon) has already been widely described $[19,20]$ and it was shown that lattice scattering effects would dominate carriers' behaviour. However, many of the effects described were on the bulk property while our principal focus dealt with effects on the interfacial region of the silicon adatom. Hence, we suspect that we could disregard all Hall effects at this temperature. Between both the $n$ - and $p$-type substrate, the initial mechanism for the formation of $\mathrm{Si}-\mathrm{O}-\mathrm{C}$ bonds on the $\mathrm{Si}-\mathrm{H}$ surface was relatively similar, occurring via the abstraction of hydrogen in the nucleophilic route $[17,18]$ with the liberation of hydrogen during the process. However, from the start, the XPS Si2p spectrum on both the $n$-type silicon (111) and $p$-type silicon (111) showed the formation of Si-O-C bonding but their overall profiles were starkly different. As shown in Figure 2, the Si2p assignment for Si2 $p_{3 / 2}$ and Si2 $p_{1 / 2}$ at the nominal position of 99-100 eV was found to exhibit relatively different FWHM values with the $p$-type silicon, showing broader dual peaks ( $F W H M=2.3 \mathrm{~nm}$ ) (Figure 2a) compared to the $n$-type silicon $($ FWHM $=0.9 \mathrm{~nm}$ ) (Figure 2b). On the other hand, both spectra showed the emergence of the peak at $102.2-102.5 \mathrm{eV}$, representative of the $\mathrm{Si}-\mathrm{O}-\mathrm{C}$ linkage to the surface $[17,21,22]$. The differences of peak profile and the changes in the FWHM of the Si2p could be attributed to the distribution of chemically shifted Si2p lines arising from surface roughening as reported previously in literature [23,24]. In fact, it has been shown that surface roughening does have a major contribution to the overall spatial intensity of the photoelectron [25-27]. When this comparison was made with the silicon (100) surfaces, the Si-O-C levels were even more profound, especially for the $p$-type silicon (100) (Figure 2c) and $n$-type silicon (100) (Figure 2d). In fact, there was a notable quenching/lowering of the nominal Si2 $\mathrm{p}_{3 / 2}$ and $\mathrm{Si} 2 \mathrm{p}_{1 / 2}$ at $99-100 \mathrm{eV}$ for both surfaces with a profound peak centering at 101.9-102.1 eV. This may suggest that for both (100) surfaces, alcohol etching was more extensive compared to the (111) surfaces.
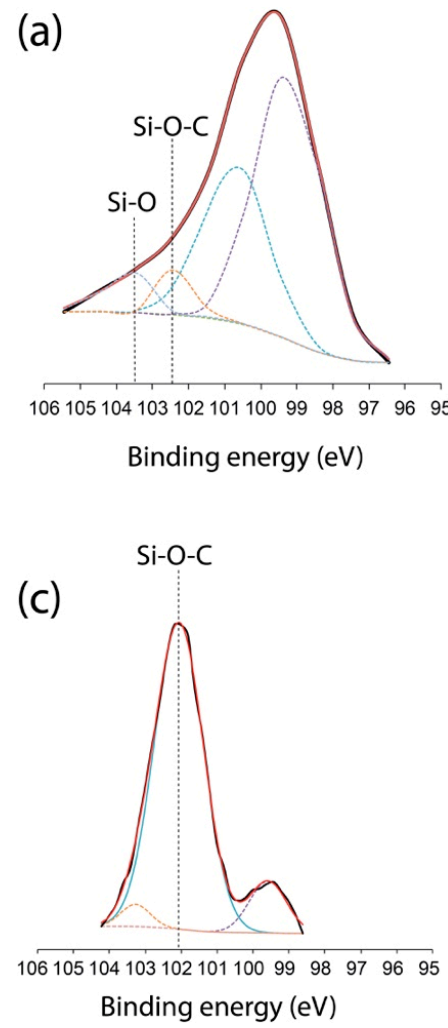
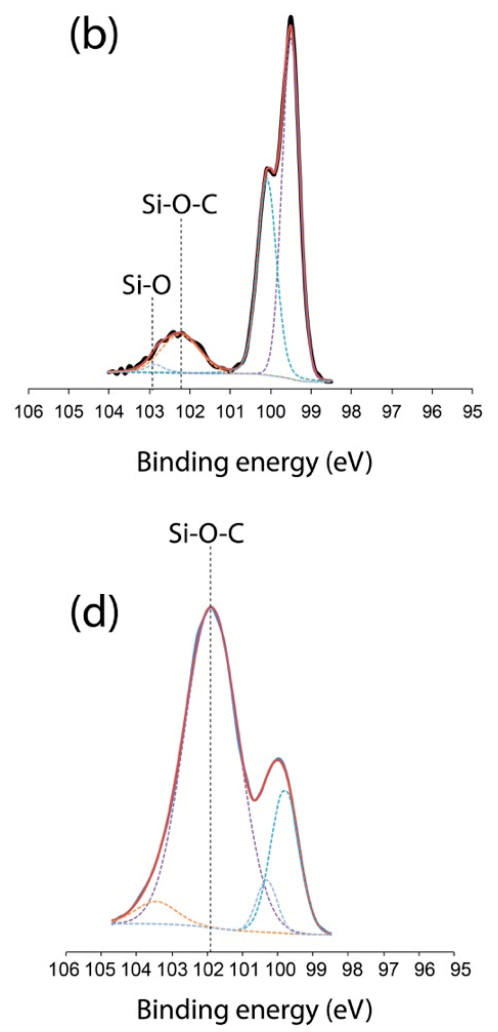

Figure 2. X-ray photoelectron spectroscopy (XPS) Si2p spectrum of (a) $p$-type silicon (111); (b) n-type silicon (111); (c) $p$-type silicon (100) and (d) $n$-type silicon (100). Note the emergence of the Si-O-C bond centering at $\sim 102 \mathrm{eV}$. 
In order to understand the exact nature of the roughening, AFM was performed on these surfaces. It was firstly to state that HF treatment on $p$-type does not typically generate an atomically flat surface while it was possible to obtain that from $n$-type silicon. As shown in Figure 3, in order to evaluate the surface roughening effect, the authors felt that it was prudent to compare the surface topography before and after HF treatment ( $30 \mathrm{~s}$ ) so as to demonstrate that the final etching conditions arised solely from the grafting of the alcohol to the silicon surface. All the surface morphologies of various doping and orientation were as displayed, from pristine, HF treated and alcohol reacted surfaces in Figure 3 and it was immediately obvious that all $p$-type surfaces exhibit a much rougher topography than compared to $n$-type. In fact, despite the crystal orientation, this result seemingly suggests that the roughening was more prominent with the $p$-type surfaces than the $n$-type in general although it must be stated that the starting roughness on (111) silicon was already much lower compared to the (100) crystal orientation. Cross-section profiling showed that $p$-type (111) experienced an increase in surface roughness upon alcohol functionalization, from an initial RMS value of $0.09 \mathrm{~nm} \pm 0.05 \mathrm{~nm}$ (pristine unmodified silicon) to a final RMS of $0.86 \mathrm{~nm} \pm 0.15$. On the other hand, there was a near negligible change of surface roughness on the $n$-type silicon before functionalization (RMS: $0.06 \mathrm{~nm} \pm 0.03$ ) and after the reaction (RMS: $0.11 \mathrm{~nm} \pm 0.05)$. On the other hand, the roughening effects were even more profound for both $p$ - and $n$-type silicon (100) surfaces, with RMS registering at $2.58 \mathrm{~nm} \pm 0.03$ for the $p$-type and $1.05 \mathrm{~nm} \pm 0.32$ for the $n$-type respectively. When these data were corroborated with the XPS in Figure 2, it was clearly noticeable that the effects of grafting did not affect (111) the surface as much as (100), as both Figure $2 a, b$ clearly exhibit the notable levels of $S i 2 p_{3 / 2}$ and $S i 2 p_{1 / 2}$ at $99-100 \mathrm{eV}$. Of the set of data obtained from XPS, $p$-type silicon (100) showed the lowest level of Si2 $\mathrm{p}_{3 / 2}$ and $\mathrm{Si} 2 \mathrm{p}_{1 / 2}$ at $99-100 \mathrm{eV}$ and this suggested that much of the $\mathrm{Si}-\mathrm{Si}$ linkage on the surface of the substrate was disrupted and our AFM seemed to confirm this finding.

Since the observed chemical reaction to the surface was very similar for both crystal orientations and XPS had successfully indicated the formation of the $\mathrm{Si}-\mathrm{O}-\mathrm{C}$ linkage, surface roughening could only be conceived as an artefact arising from a collective influence of doping chemistry and crystal orientation. This was further confirmed by wettability studies as the water contact angle for the (111) $p$-type and the (111) $n$-type was registered at $87.2^{\circ} \pm 4.6^{\circ}$ and $70.8^{\circ} \pm 0.8^{\circ}$, further showing the changes in wettability induced from surface roughening. We found that the hydrophobicity was lower for the (100) surfaces (see Figure 4) and this may be attributed to the lower packing order of the adatom of silicon (100) on the surface of the silicon wafer compared to the silicon (111) surface.

Firstly, it is important to state that the focus of this paper is to examine the mechanism behind the $\mathrm{Si}-\mathrm{Si}$ backbond weakening mechanism rather than describing the entirety of the etching process. Hence, to describe the changes to the $p$-type silicon (111) surface roughness and the concurrent absence of roughening on $n$-type silicon, it is important to appreciate that atomically flat hydrogen-terminated (111) silicon surfaces are generally less likely to be etched or roughened due to the co-planar arrangement of atoms at the surface that renders it relatively stable. Thus, the weakening of the $\mathrm{Si}-\mathrm{Si}$ backbond is deemed to be difficult due to the sterics on the surface [28]. For our case, in the first phase of the reaction, the alcohol grafting and the subsequent formation of the $\mathrm{Si}-\mathrm{O}-\mathrm{C}$ linkage on the surface would induce a polarization of the surface. This results in the oxygen species pulling the electron closer towards the silicon surface atoms due to its higher electronegativity. For $p$-type silicon, this could inherently result in the weakening of the silicon-silicon backbond that subsequently permits its breakage. Such weakening is, however, dependent upon the doping type, as the ease of the subsequent breakage of the silicon-silicon backbond depends on the concentration of valence band holes at the substratum surface. 


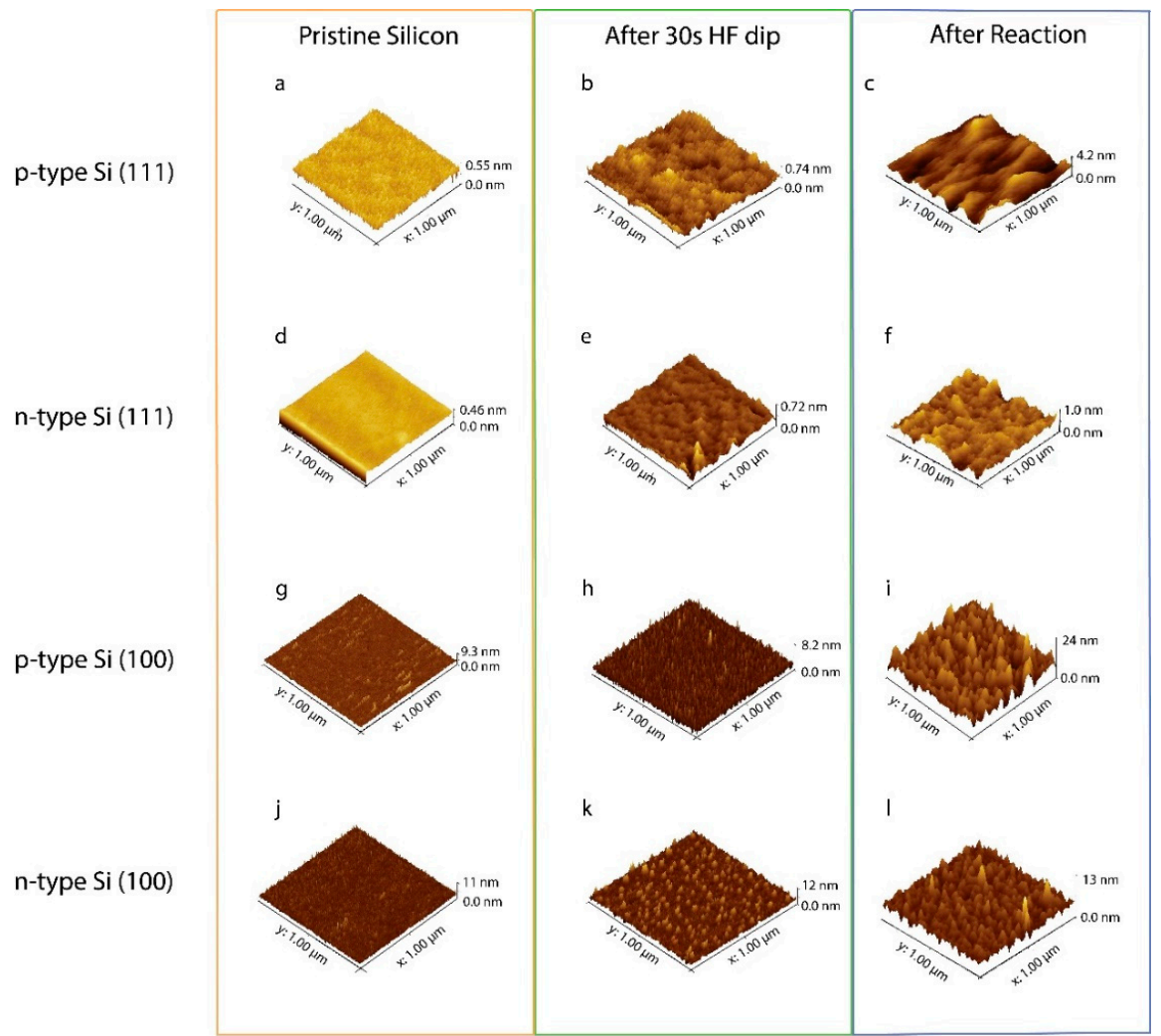

Figure 3. Atomic force microscopy (AFM) measurement of three conditions, $(\mathbf{a}, \mathbf{d}, \mathbf{g}, \mathbf{j})$ pristine silicon of various orientations and doping; $(\mathbf{b}, \mathbf{e}, \mathbf{h}, \mathbf{k})$ after a $30 \mathrm{~s}$ HF treatment and $(\mathbf{c}, \mathbf{f}, \mathbf{i}, \mathbf{l})$ after thermal reaction with alcohol.
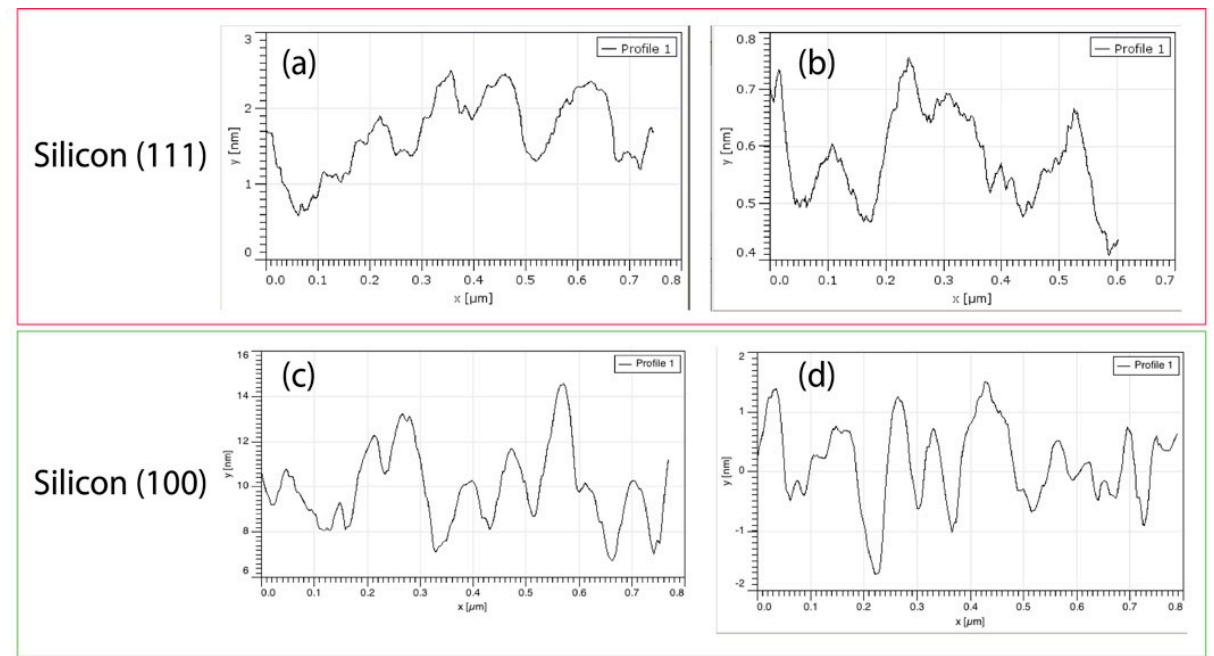

\begin{tabular}{|c|c|c|}
\multicolumn{3}{|c|}{ Contact angle } \\
\hline & p-type & n-type \\
\hline$(111)$ & $87.2^{\circ} \pm 4.6^{\circ}$ & $70.8^{\circ} \pm 0.8^{\circ}$ \\
\hline$(100)$ & $79.7^{\circ} \pm 2.3^{\circ}$ & $66.8^{\circ} \pm 3.6^{\circ}$ \\
\hline
\end{tabular}

\begin{tabular}{|c|c|c|}
\hline \multicolumn{3}{|c}{ Rms } \\
\hline$(111)$ & p-type & n-type \\
\hline$(100)$ & $0.86 \mathrm{~nm} \pm 0.15$ & $0.11 \mathrm{~nm} \pm 0.05$ \\
\hline
\end{tabular}

Figure 4. Roughness profile of silicon (111) after grafting for (a) $p$-type and (b) $n$-type while the profile for silicon (100) was also displayed for (c) $p$-type and (d) $n$-type. 
For $p$-type silicon (111), the large density of holes helps weaken the Si-Si bond at the surface, and this allows for nucleophilic attack according to the Gerischer's mechanism [29,30]. This offers an explanation for the roughening of the semiconductor upon the formation of the $\mathrm{Si}-\mathrm{O}-\mathrm{C}$ on the surface, inducing a change in the surface dipole (Figure 4). However, it would be naïve to perceive that alcohol would then proceed to etch the surface as in HF treatment. In the typical HF reaction to the surface, the Si-F bond energy is $\sim 160 \mathrm{kcal} \mathrm{mol}^{-1}$ while the $\mathrm{Si}-\mathrm{O}$ bond energy is $111 \mathrm{kcal} \mathrm{mol}^{-1}$ [31]. The electron pull from the $\mathrm{Si}-\mathrm{F}$ forming to the surface is strong enough to result in the breakage of the subsequent $\mathrm{Si}-\mathrm{Si}$ backbond and this ultimately results in the liberation of a single $\mathrm{SiF}_{4}$ from the silicon bulk material, hence creating the etching event. Instead, $\mathrm{Si}-\mathrm{O}-\mathrm{C}$ type linkage does not exert similar pull but only weakens the underlying $\mathrm{Si}-\mathrm{Si}$ backbond, making it more susceptible to nucleophilic attack from the alcohol reactant. Since the reaction volume of the ethynylbenzyl alcohol was only $0.3 \mathrm{M}$ in $5 \mathrm{~mL}$ of mesitylene and accounting for solute depletion and weaker Si-O linkage compared to $\mathrm{Si}-\mathrm{F}$, a gradual roughening of the surface initiated at surface defects is then well expected. This is in agreement with the observations reported by Hacker et al. [7] on $p$-type silicon substrate upon the formation of $\mathrm{Si}-\mathrm{O}-\mathrm{C}$.

The absence of surface roughening in (111) $n$-type silicon is similarly attributed to the lower density of holes (that are here minority carriers) when silicon is doped with phosphorus (arsenic in the case of the $n$-type silicon (100)). Typically, relevant hole densities can be generated only by applying an electrical bias, by photon absorption on the surface [32] or via hole injection from an oxidant [33] - but none of these effects were present in the current experimental conditions. Thus, the ethynylbenzyl alcohol reacted first to the surface via insertion to form a $\mathrm{Si}-\mathrm{O}-\mathrm{C}$ linkage but then it does not possess enough impetus to break the $\mathrm{Si}-\mathrm{Si}$ backbond due to the electron compensation arising from the sea of electron-rich phosphorous dopant (Figure 5). This is consistent with the observation that on atomically flat $n$-type silicon, roughening of the surface upon formation of the $\mathrm{Si}-\mathrm{O}-\mathrm{C}$ linkage is localised along step edges while the terrace flat surface remains largely untouched (apart from defective sites) [8]. This is logical as step edge dangling bonds are the only ones that may be susceptible to Si-Si backbond weakening. Furthermore, the atomic flatness of the surface lattice does not permit any further attacks of Si-Si bonding [28], in good agreement with our observations.

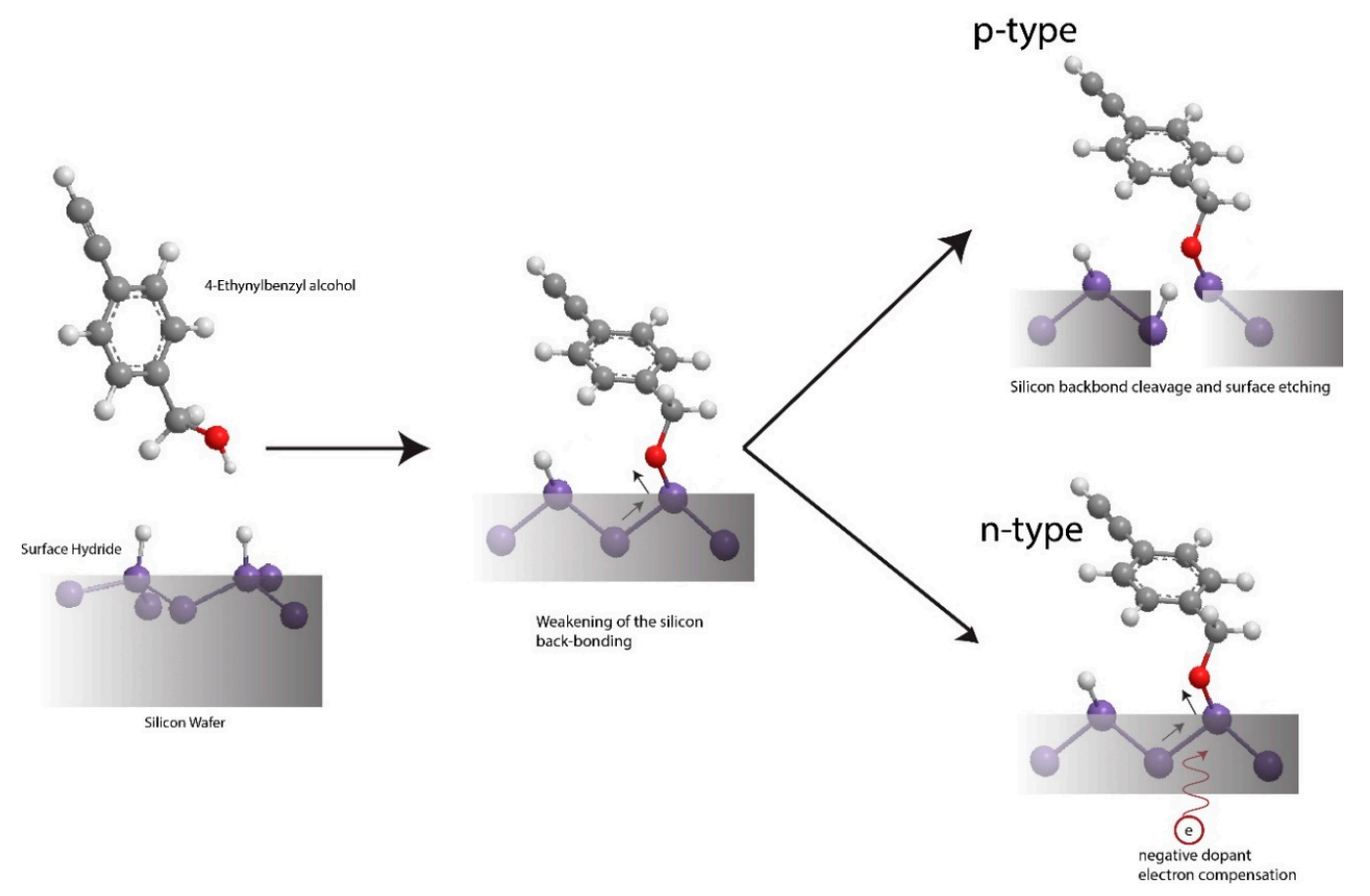

Figure 5. Schematic representation of the weakening of the Si-Si backbond on $p$-type and dopant compensation on the $n$-type silicon surface. 
On the other hand, these physical rationales and processes were relatively similar for the p-type silicon (100) surfaces with some notable differences: a HF acid treated (100) surface would exhibit inherent roughening as well as a mixed population of silicon monohydride, bihydride and trihydrides [34]. Hence, it would be expected that the surface would be inherently rougher than that of the (111) orientation considering the presence of more surface defects. However, what was more interesting was the fact that for the silicon (100), the $n$-type also demonstrated less roughening as compared to the $p$-type (100), which exhibited almost negligible roughness from the initial HF dip treatment. This led us to suspect that the underlying dopant was the main causative agent for such findings and this was very much in agreement with the hypothesis as advocated in the previous paragraphs. Pertaining to the reduced contact angles as shown by the (100) surfaces in general, we considered that this arose from less ordered surface adatoms that did not permit for good passivation in general.

\section{Summary and Conclusions}

In summary, we established that alcohol interfacing at elevated temperatures to the silicon surface might induce surface roughening that is highly dependent on the doping as well as the crystal orientation of the substrate. It was found that a well ordered adatom packing arrangement on the top surface may help influence the alcohol etching extensiveness but the type of dopant plays a significant role pertaining to the extent of the etching. It appeared that $n$-type doped silicon was able to resist etching better than $p$-type silicon and this was attributed to the dopant that helped compensate the electronegative pull of the oxygen binding to the silicon. These physical results are consistent to those reported previously in the literature while a more detailed mechanism for surface roughening could be advocated in the future, taking into account the synergic effect of surface polarization and hole availability.

Acknowledgments: The work was carried out with assistance from university grant (CMU-1055918D) and grant under Ministry of Science and Technology in Taiwan (MOST 105-2218-E-039-002) and (MOST 106-2221-E-039-005). The authors would also like to express their gratitude to Dario Narducci and Siti Ngalim for their contributions in preliminary discussion of this work.

Author Contributions: Joline Tung had performed the surface modifications as well as the surface analysis. Yit Lung Khung had conceived the project concept as well as having written the majority of this manuscript.

Conflicts of Interest: The authors declare no conflict of interest.

\section{References}

1. Boukherroub, R.; Morin, S.; Bensebaa, F.; Wayner, D.D.M. New synthetic routes to alkyl monolayers on the Si(111) surface. Langmuir 1999, 15, 3831-3835. [CrossRef]

2. Buriak, J.M. Silicon-carbon bonds on porous silicon surfaces. Adv. Mater. 1999, 11. [CrossRef]

3. Buriak, J.M.; Stewart, M.P.; Geders, T.W.; Allen, M.J.; Choi, H.C.; Smith, J.; Raftery, D.; Canham, L.T. Lewis acid mediated hydrosilylation on porous silicon surfaces. J. Am. Chem. Soc. 1999, 121, 11491-11502. [CrossRef]

4. Cleland, G.; Horrocks, B.R.; Houlton, A. Direct functionalization of silicon via the self-assembly of alcohols. J. Chem. Soc. Faraday Trans. 1995, 91, 4001-4003. [CrossRef]

5. Radi, A.; Leung, K.T. Competitive bonding of amino and hydroxyl groups in ethanolamine on $\operatorname{Si}(100) 2 \times 1$ : Temperature-dependent X-ray photoemission and thermal desorption studies of nanochemistry of a double-chelating agent. Mater. Express 2011, 1, 144-153. [CrossRef]

6. Khung, Y.L.; Ngalim, S.H.; Scaccabarozi, A.; Narducci, D. Thermal and uv hydrosilylation of alcohol-based bifunctional alkynes on $\mathrm{Si}(111)$ surfaces: How surface radicals influence surface bond formation. Sci. Rep. 2015, 5. [CrossRef] [PubMed]

7. Hacker, C.A.; Anderson, K.A.; Richter, L.J.; Richter, C.A. Comparison of Si-O-C interfacial bonding of alcohols and aldehydes on $\mathrm{Si}(111)$ formed from dilute solution with ultraviolet irradiation. Langmuir 2005, 21, 882-889. [CrossRef] [PubMed] 
8. Boukherroub, R.; Morin, S.; Sharpe, P.; Wayner, D.D.M.; Allongue, P. Insights into the formation mechanisms of Si-or monolayers from the thermal reactions of alcohols and aldehydes with Si(111)-H. Langmuir 2000, 16, 7429-7434. [CrossRef]

9. Michalak, D.J.; Amy, S.R.; Esteve, A.; Chabal, Y.J. Investigation of the chemical purity of silicon surfaces reacted with liquid methanol. J. Phys. Chem. C 2008, 112, 11907-11919. [CrossRef]

10. Michalak, D.J.; Rivillon, S.; Chabal, Y.J.; Esteve, A.; Lewis, N.S. Infrared spectroscopic investigation of the reaction of hydrogen-terminated, (111)-oriented, silicon surfaces with liquid methanol. J. Phys. Chem. B 2006, 110, 20426-20434. [CrossRef] [PubMed]

11. Sieval, A.B.; Linke, R.; Heij, G.; Meijer, G.; Zuilhof, H.; Sudholter, E.J.R. Amino-terminated organic monolayers on hydrogen-terminated silicon surfaces. Langmuir 2001, 17, 7554-7559. [CrossRef]

12. Sieval, A.B.; van den Hout, B.; Zuilhof, H.; Sudholter, E.J.R. Molecular modeling of covalently attached alkyl monolayers an the hydrogen-terminated Si(111) surface. Langmuir 2001, 17, 2172-2181. [CrossRef]

13. Coletti, C.; Marrone, A.; Giorgi, G.; Sgamellotti, A.; Cerofolini, G.; Re, N. Nonradical mechanisms for the uncatalyzed thermal functionalization of silicon surfaces by alkenes and alkynes: A density functional study. Langmuir 2006, 22, 9949-9956. [CrossRef] [PubMed]

14. Wang, X.Y.; Ruther, R.E.; Streifer, J.A.; Hamers, R.J. UV-induced grafting of alkenes to silicon surfaces: Photoemission versus excitons. J. Am. Chem. Soc. 2010, 132, 4048-4049. [CrossRef] [PubMed]

15. Buriak, J.M. Illuminating silicon surface hydrosilylation: An unexpected plurality of mechanisms. Chem. Mater. 2014, 26, 763-772. [CrossRef]

16. Cai, W.; Lin, Z.; Strother, T.; Smith, L.M.; Hamers, R.J. Chemical modification and patterning of iodine-terminated silicon surfaces using visible light. J. Phys. Chem. B 2002, 106, 2656-2664. [CrossRef]

17. Khung, Y.L.; Ngalim, S.H.; Meda, L.; Narducci, D. Preferential formation of Si-O-C over Si-C linkage upon thermal grafting on hydrogen-terminated silicon (111). Chem. Eur. J. 2014, 20, 15151-15158. [CrossRef] [PubMed]

18. Khung, Y.L.; Ngalim, S.H.; Scaccabarozzi, A.; Narducci, D. Formation of stable Si-O-C submonolayers on hydrogen-terminated silicon (111) under low-temperature conditions. Beilstein J. Nanotechnol. 2015, 6, 19-26. [CrossRef] [PubMed]

19. Arora, N.D.; Hauser, J.R.; Roulston, D.J. Electron and hole mobilities in silicon as a function of concentration and temperature. IEEE Trans. Electron. Devices 1982, 29, 292-295. [CrossRef]

20. Fischetti, M.V.; Ren, Z.; Solomon, P.M.; Yang, M.; Rim, K. Six-band k center dot p calculation of the hole mobility in silicon inversion layers: Dependence on surface orientation, strain, and silicon thickness. J. Appl. Phys. 2003, 94, 1079-1095. [CrossRef]

21. Avila, A.; Montero, I.; Galan, L.; Ripalda, J.M.; Levy, R. Behavior of oxygen doped sic thin films: An X-ray photoelectron spectroscopy study. J. Appl. Phys. 2001, 89, 212-216. [CrossRef]

22. Li, N.; Hu, P.; Zhang, X.; Liu, Y.; Han, W. Effects of oxygen partial pressure and atomic oxygen on the microstructure of oxide scale of ZrB2-SiC composites at 1500 degrees C. Corros. Sci. 2013, 73, 44-53. [CrossRef]

23. Thogersen, A.; Selj, J.H.; Marstein, E.S. Oxidation effects on graded porous silicon anti-reflection coatings. J. Electrochem. Soc. 2012, 159, D276-D281. [CrossRef]

24. Guerrero-Lemus, R.; Moreno, J.D.; Martin-Palma, R.J.; Ben-Hander, F.; Martinez-Duart, J.M.; Fierro, J.L.G.; Gomez-Garrido, P. Influence of oxidation and carbon-containing contamination in the stabilization of the luminescence in porous silicon. Thin Solid Films 1999, 354, 34-37. [CrossRef]

25. Gunter, P.L.J.; Gijzeman, O.L.J.; Niemantsverdriet, J.W. Surface roughness effects in quantitative XPS: Magic angle for determining overlayer thickness. Appl. Surf. Sci 1997, 115, 342-346. [CrossRef]

26. Olejnik, K.; Zemek, J. Applicability of magic angle for angle-resolved X-ray photoelectron spectroscopy of corrugated SiO2/Si surfaces: Monte carlo calculations. Surf. Sci. 2008, 602, 2581-2586. [CrossRef]

27. Zemek, J.; Olejnik, K.; Klapetek, P. Photoelectron spectroscopy from randomly corrugated surfaces. Surf. Sci. 2008, 602, 1440-1446. [CrossRef]

28. Michalak, D.J.; Amy, S.R.; Aureau, D.; Dai, M.; Esteve, A.; Chabal, Y.J. Nanopatterning Si(111) surfaces as a selective surface-chemistry route. Nat. Mater. 2010, 9, 266-271. [CrossRef] [PubMed]

29. Gerischer, H.; Mindt, W. The mechanisms of the decomposition of semiconductors by electrochemical oxidation and reduction. Electrochim. Acta 1968, 13, 1329-1341. [CrossRef]

30. Kolasinski, K.W. Etching of silicon in fluoride solutions. Surf. Sci. 2009, 603, 1904-1911. [CrossRef] 
31. Walsh, R. Bond-dissociation energy values in silicon-containing compounds and some of their implications. Acc. Chem. Res. 1981, 14, 246-252. [CrossRef]

32. Lehmann, V. The physics of macropore formation in low doped n-type silicon. J. Electrochem. Soc. 1993, 140, 2836-2843. [CrossRef]

33. Nahm, K.S.; Seo, Y.H.; Lee, H.J. Formation mechanism of stains during Si etching reaction in HF-oxidizing agent $\mathrm{H}_{2} \mathrm{O}$ solutions. J. Appl. Phys. 1997, 81, 2418-2424. [CrossRef]

34. Shane, S.F.; Kolasinski, K.W.; Zare, R.N. State-specific study of hydrogen desorption from $\operatorname{Si}(100)-(2 \times 1)$ : Comparison of disilane and hydrogen adsorption. J. Vac. Sci. Technol. A Vac. Surf. Films 1992, 10, 2287-2291. [CrossRef] 